\title{
Low dose of moxonidine within the rostral ventrolateral medulla improves the baroreflex sensitivity control of sympathetic activity in hypertensive rat
}

\author{
Jia-ling WANG ${ }^{1,2, \#, ~ L o n g ~ W A N G ~}{ }^{3, \#}$, Zhao-tang WU ${ }^{4, \#}$, Wen-jun YUAN ${ }^{1}$, Ding-feng $\mathrm{SU}^{4}$, Xin NI ${ }^{1}$, Jian-jun YAN ${ }^{5, *}$, Wei-zhong \\ WANG $^{1, *}$ \\ Department of ${ }^{1}$ Physiology and ${ }^{4}$ Pharmacology, Second Military Medical University, Shanghai 200433, China; ${ }^{2}$ Department of \\ Emergency, Changhai Hospital, Shanghai 200433, China; ${ }^{3}$ Shanghai Research Center for Biomodel Organism, Shanghai 200433, \\ China; ${ }^{5}$ The First Department of Hepatic Surgery, Eastern Hepatobiliary Surgery Hospital, Shanghai 200433, China
}

Aim: To determine the effects of the centrally antihypertensive drug moxonidine injected into the rostral ventrolateral medulla (RVLM) on baroreflex function in spontaneously hypertensive rats (SHR).

Methods: Baroreflex sensitivity control of renal sympathetic nerve activity (RSNA) and barosensitivity of the RVLM presympathetic neurons were determined following application of different doses of moxonidine within the RVLM.

Results: Three doses $(0.05,0.5$, and $5 \mathrm{nmol}$ in $50 \mathrm{~nL})$ of moxonidine injected bilaterally into the RVLM dose-dependently reduced the baseline blood pressure (BP) and RSNA in SHR. At the highest dose $(5 \mathrm{nmol}$ ) of moxonidine injection, the maximum gain $(1.24 \% \pm 0.04 \% / \mathrm{mmHg})$ of baroreflex control of RSNA was significantly decreased. However, the lower doses $(0.05$ and $0.5 \mathrm{nmol})$ of moxonidine injection into the RVLM significantly enhanced the baroreflex gain (2.34\% $\pm 0.08 \%$ and $2.01 \% \pm 0.07 \% / \mathrm{mmHg})$. The moxonidine-induced enhancement in baroreflex function was completely prevented by the imidazoline receptor antagonist efaroxan but not by the $\alpha_{2}$-adrenoceptor antagonist yohimbine. A total of 48 presympathetic neurons were recorded extracellularly in the RVLM of SHR. Iontophoresis of applied moxonidine (30-60 nA) dose-dependently decreased the discharge of RVLM presympathetic neurons but also significantly increased the barosensitivity of RVLM presympathetic neurons.

Conclusion: These data demonstrate that a low dose of moxonidine within the RVLM has a beneficial effect on improving the baroreflex function in SHR via an imidazoline receptor-dependent mechanism.

Keywords: centrally-acting drug; $I_{1}$-imidazoline receptor; microinjection; extracellular recording; presympathetic neuron

Acta Pharmacologica Sinica (2009) 30: 1594-1600; doi: 10.1038/aps.2009.165

\section{Introduction}

The central antihypertensive drug moxonidine, which has a weak affinity for the $a_{2}$-adrenoceptor $\left(a_{2} A R\right)$, is generally described as a selective $I_{1}$-imidazoline receptor $\left(I_{1} R\right)$ agonist that lowers blood pressure (BP) by decreasing sympathetic activity within the central nervous system ${ }^{[1]}$. It is well known that the rostral ventrolateral medulla (RVLM) plays a critical role in tonic and reflex control of sympathetic outflow and $\mathrm{BP}^{[2]}$. The presympathetic neurons in the RVLM project

\footnotetext{
\# These authors equally contribute to this work.

* To whom correspondence should be addressed.

E-mail wangwz68@hotmail.com (Wei-zhong WANG) rian1971@sina.com (Jian-jun YAN)

Received 2009-07-22 Accepted 2009-10-19
}

directly to sympathetic preganglionic neurons in the spinal cord and are recognized as a major target responsible for the action of centrally acting antihypertensive agents such as clonidine and moxonidine ${ }^{[3,4]}$.

In many cardiovascular diseases such as hypertension, the baroreflex, a prime regulator for sympathetic outflow, is blunted, which is closely related to the mortality of this disease $^{[5,6]}$. Improvement of baroreflex impairment and reduction of blood pressure variability have become an important therapeutic strategy for hypertension ${ }^{[7]}$. Interestingly, in addition to sympathoinhibition, central antihypertensive drugs have an effect on the arterial baroreflex sensitivity ${ }^{[8,9]}$. Barodenervation also significantly modifies the effects of centrally-acting drugs $^{[10]}$. The central antihypertensive effects of clonidine are 
reported to be dependent on enhancement of baroreflex inhibitory control in hypertension ${ }^{[11]}$. However, it is interesting that the differential effects of centrally-acting drugs on the baroreflex sensitivity are described in previous studies. For example, Head et al reported a series of studies in anesthetized or conscious rabbit showing that the centrally-acting drug rilmenidine via systemic or central administration led to a decrease in baroreflex control of sympathetic activity ${ }^{[12-14]}$. In contrast, it is reported that the centrally-acting drugs (clonidine and moxonidine) are capable of enhancing baroreflex control of heart rate $(\mathrm{HR})$ in normotensive or hypertensive models ${ }^{[15,16]}$. The reasons for these conflicting findings are not fully understood. In addition, the effect of centrally-acting drugs, especially the $\mathrm{I}_{1} \mathrm{R}$ agonist moxonidine, on baroreflex control of sympathetic activity has not been extensively studied in hypertension. Here, this study was designed to determine the effect of different doses of moxonidine on baroreflex sensitivity control of sympathetic activity in the spontaneously hypertensive rat (SHR) at the level of the RVLM presympathetic neurons.

\section{Materials and methods}

\section{Animals}

Male 18 to 20-week-old SHR were provided by the Animal Center of our university. All the animal procedures were performed in compliance with institutional animal care guidelines. Methods for general procedures, recording of renal sympathetic nerve activity (RSNA), RVLM microinjection, extracellular recording, iontophoresis, and histological procedures were similar to those described previously ${ }^{[17,18]}$.

\section{General surgical procedures}

Briefly, rats were anesthetized with urethane $(800 \mathrm{mg} / \mathrm{kg}$ ip) and a-chloralose (40 mg/kg ip), and the trachea was cannulated to facilitate mechanical respiration. The right common carotid artery was catheterized for BP measurement by a PowerLab system (ADInstruments). Based on the BP pulse, the mean arterial pressure (MAP) and heart rate (HR) were calculated and displayed by a recording software (Chat 5.0, ADInstruments). The jugular and femoral veins were cannulated for supplemental anesthesia ( $a$-chloralose, $10 \mathrm{mg} /$ $\mathrm{kg}$ ), neuromuscular blockade (gallamine triethiodide, $10 \mathrm{mg}$ / $\mathrm{kg}$ ), and other drug administrations. The rat was placed in a stereotaxic frame, and the dorsal surface of the medulla was surgically exposed. Body temperature was kept at $37^{\circ} \mathrm{C}$.

\section{Recording of RSNA}

The renal sympathetic nerves were exposed and placed on a pair of recording electrodes. The activity of RSNA was amplified and recorded. Baseline RSNA was taken as 100\% from the absolute value after the noise level was subtracted.

\section{RVLM microinjection}

Microinjections were made from a four-barrel micropipette (20-50 $\mu \mathrm{m}$ diameter). The coordinates for RVLM were 2.0-2.5 $\mathrm{mm}$ rostral and 1.8-2.1 $\mathrm{mm}$ lateral to calamus scriptorius and 2.8-3.2 mm ventral to the dorsal surface of the medulla. The injection was made over a period of 5-10 s and the injection volume $(50 \mathrm{~nL})$ was carefully measured by observing the movement of the fluid meniscus along a reticule in a microscope. The RVLM was chemically identified by L-glutamate (1 nmol) microinjection. All drugs for microinjection were purchased from Sigma and dissolved in artificial cerebrospinal fluid (aCSF, pH 7.4). The time interval between bilateral injections was within $3 \mathrm{~min}$. The doses of antagonists were lower in the work compared to regular dose applied in previous work because the improvement of baroreflex function in SHR was induced by $1 \%-10 \%$ of regular dose of the agonist moxonidine. On the other hand, low doses of antagonists injected into the RVLM were not able to significantly change the basal BP and RSNA, which will be helpful to more accurately assess the baroreflex function before and after treatments. In addition, our preliminary data demonstrated no significant change in baseline BP and RSNA, baroreflex function in response to such a low dose as $0.05 \mathrm{nmol}$ efaroxan or $5 \mathrm{pmol}$ yohimbine in the RVLM. Finally, $50 \mathrm{~nL}$ of $2 \%$ pontamine sky blue solution was injected into the RVLM to mark the site.

\section{Extracellular recording and iontophoresis}

For RVLM unit recording, a laminectomy $\left(\mathrm{T}_{1-3}\right)$ was performed and a stimulating electrode was placed in the dorsolateral funiculus of spinal segment $\mathrm{T}_{2}$ to allow for antidromic stimulation. A vascular occluder (Harvard) was placed around the descending thoracic aorta above the diaphragm for baroreceptor stimulation. A five-barrel micropipette was used for neuronal recording and iontophoresis. Extracellular single-unit recordings were made from spontaneously active neurons in the RVLM with central barrel ( $2 \%$ pontamine sky blue dissolved in $0.5 \mathrm{~mol} / \mathrm{L}$ sodium acetate). Signals were preamplified, and subsequently fed into a window discriminator and monitored on an oscilloscope. Corresponding to each spike, the discriminator generated a digitized pulse for further computerized analysis. The RVLM presympathetic neurons were identified by barosensitivity and axonal projection according to previous studies ${ }^{[19,20]}$.

For iontophoresis, one barrel of the five-barreled microelectrode contained $2 \mathrm{~mol} / \mathrm{L} \mathrm{NaCl}$ for automatic current balance, and remaining barrels were filled by drug solutions for iontophoretic application (100 mmol/L L-glutamate; $100 \mathrm{mmol} / \mathrm{L}$ moxonidine). We first tested the neuronal sensitivity to iontophoretic $L$-glutamate because it was believed to depolarize exclusively the cell body of a neuron ${ }^{[21]}$. In some experiments, the possibility of current artifacts was tested by passing a negative current through the balance tube. No significant current artifacts were observed with this test. In order to confirm that the spike was from a single unit, an overlay (50 sweeps) of the action potential trajectories was performed before and after treatments. At the end of the experiment, the recording site was marked by electrophoretic application of pontamine sky blue dye.

\section{Baroreflex sensitivity}

Baroreflex sensitivity control of RSNA was generated by mea- 
suring the RSNA responses to a decrease and then an increase in $\mathrm{BP}$ by an intravenous bolus injection of nitroglycerin and phenylephrine. MAP and RSNA were averaged over $2 \mathrm{~s}$ intervals and fitted to a sigmoid logistic function to produce MAP-RSNA curve using a non-linear regression program (SigmaPlot 10.0). Five parameters (RSNA range, slope coefficient, midpoint of the range, minimum RSNA, maximum gain) were calculated for evaluating the baroreflex sensitivity control of RSNA. Barosensitivity of presympathetic neurons in the RVLM was evaluated by the slope of correlation of change between decrease in neuronal discharge and increase in MAP (0 to $50 \mathrm{mmHg}$ ) by aortic occlusion (10-15 s).

\section{Histological analysis}

At the end of the experiments, the brains were removed from the skulls, placed in $10 \%$ formalin and sectioned to verify the microinjection and recording sites. According to the standard atlas of Paxinos and Watson ${ }^{[22]}$, the injection and recording sites were located in the rostral medulla, just ventromedial to the compact portion of nucleus ambiguous, similar to the sites that we have published previously ${ }^{[23,24]}$.

\section{Data analysis}

All values are expressed as mean \pm SEM. Student's $t$ test or ANOVA (one or two-way) was used for statistical analyses by Sigmastat software (version 3.5). A value of $P<0.05$ was considered statistically significant.

\section{Results}

\section{Baroreflex sensitivity control of RSNA}

As shown in Table 1, the basal MAP and HR values were not different among the various groups of SHR rats used for microinjection protocols. Generally, three doses $(0.05,0.5$, and $5 \mathrm{nmol}$ ) of bilateral injection of moxonidine into the RVLM produced a significant fall in MAP, HR, and RSNA compared to vehicle injection (Table 1). These effects of moxonidine were dose-dependent. The effective time of moxonidine was significantly longer in the highest dose (more than $60 \mathrm{~min}$ ) than in low dose groups (10-30 min). The baroreflex sensitivity control of RSNA was measured before and $10 \mathrm{~min}$ after moxonidine injections. As shown in Table 2 and Figure 1A, the maximum gain $\left(\right.$ gain $_{\max }$ ) of baroreflex curve was significantly $(P<0.05)$ higher in the middle $(0.5 \mathrm{nmol})$ and the lowest doses $(0.05 \mathrm{nmol})$ of moxonidine compared to vehicle injection. In contrast, the highest dose $(5 \mathrm{nmol})$ of moxonidine led to a significant $(P<0.05)$ fall in the gain ${ }_{\max }$ of baroreflex curve. The baroreflex curves were shifted left following all moxonidine injection doses compared to control.

We further determined the receptor mechanism responsible for the enhanced effects of low dose moxonidine $(0.05 \mathrm{nmol})$ on baroreflex sensitivity (Table 2 and Figure 1B). The values of BP, HR, and RSNA were not altered following coinjection of $0.05 \mathrm{nmol}$ moxoxidine and the $\mathrm{I}_{1} \mathrm{R}$ and $\mathrm{a}_{2} \mathrm{AR}$ mixed antagonist efaroxan $(0.05 \mathrm{nmol})$ or the selective $\mathrm{a}_{2} \mathrm{AR}$ antagonist yohimbine (5 pmol) compared to the control levels (Table 1).

Table 1. Parameters of MAP, HR, and RSNA before and 10 min after moxonidine injection into the RVLM in the different groups of rats. ${ }^{b} P<0.05$ vs Vehicle and Before groups; ${ }^{\mathrm{e}} \mathrm{P}<0.05$ vs 0.05 and $0.5 \mathrm{nmol}$ moxonidine groups.

\begin{tabular}{|c|c|c|c|c|c|c|c|}
\hline & \multirow[b]{2}{*}{$n$} & \multicolumn{2}{|c|}{ MAP (mmHg) } & \multicolumn{2}{|c|}{ HR (beats/min) } & \multicolumn{2}{|c|}{ RSNA (\%) } \\
\hline & & Before & After & Before & After & Before & After \\
\hline Vehicle & 5 & $153 \pm 8$ & $155 \pm 7$ & $391 \pm 19$ & $401 \pm 17$ & 100 & $104 \pm 6$ \\
\hline Mox $0.05 \mathrm{nmol}$ & 6 & $148 \pm 7$ & $141 \pm 6$ & $382 \pm 17$ & $372 \pm 16$ & 100 & $92 \pm 4$ \\
\hline Mox $0.5 \mathrm{nmol}$ & 6 & $151 \pm 6$ & $129 \pm 5^{b}$ & $407 \pm 18$ & $339 \pm 13$ & 100 & $82 \pm 4^{b}$ \\
\hline Mox $5 \mathrm{nmol}$ & 6 & $147 \pm 6$ & $116 \pm 5^{\text {be }}$ & $397 \pm 20$ & $307 \pm 14^{\text {be }}$ & 100 & $65 \pm 7^{\text {be }}$ \\
\hline
\end{tabular}

Data are expressed as mean \pm SEM. Mox, moxonidine; Efa, efaroxan; Yoh, Yohimbine; MAP, mean arterial pressure; HR, heart rate; RSNA, renal sympathetic nerve activity.

Table 2. Parameters of baroreflex control of RSNA in response to moxonidine microinjections in the RVLM. Data are expressed as mean \pm SEM. $n=5-6$ for each group. ${ }^{\mathrm{b}} \mathrm{P}<0.05$ vs Vehicle. ${ }^{\mathrm{e}} \mathrm{P}<0.05$ vs 0.05 and $0.5 \mathrm{nmol}$ moxonidine groups.

\begin{tabular}{|c|c|c|c|c|c|}
\hline & RSNA range (\%) & Slope $(\% / \mathrm{mmHg})$ & Mid-MAP (mmHg) & Mini-RSNA (\%) & Gain $_{\max }(\% / \mathrm{mmHg})$ \\
\hline Vehicle & $122 \pm 2.1$ & $0.062 \pm 0.003$ & $174 \pm 5.2$ & $10.8 \pm 1.3$ & $1.89 \pm 0.07$ \\
\hline Mox $0.05 \mathrm{nmol}$ & $114 \pm 2.4^{b}$ & $0.082 \pm 0.004^{b}$ & $155 \pm 5.4^{\mathrm{b}}$ & $9.5 \pm 1.9$ & $2.34 \pm 0.08^{b}$ \\
\hline Mox $0.5 \mathrm{nmol}$ & $104 \pm 2.8^{b}$ & $0.078 \pm 0.003^{b}$ & $142 \pm 4.9^{b}$ & $11.3 \pm 1.6$ & $2.03 \pm 0.07^{\mathrm{b}}$ \\
\hline Mox $5 \mathrm{nmol}$ & $82 \pm 2.5^{\text {be }}$ & $0.061 \pm 0.003$ & $118 \pm 4.6^{b}$ & $10.4 \pm 1.7$ & $1.25 \pm 0.04^{\mathrm{be}}$ \\
\hline $\mathrm{Efa}+\mathrm{Mox} 0.05 \mathrm{nmol}$ & $116 \pm 3.1$ & $0.064 \pm 0.005$ & $169 \pm 5.5$ & $11.5 \pm 2.1$ & $1.86 \pm 0.06$ \\
\hline
\end{tabular}

Mox, moxonidine; Efa, efaroxan; Yoh, Yohimbine; MAP, mean arterial pressure; HR, heart rate; RSNA, renal sympathetic nerve activity. 

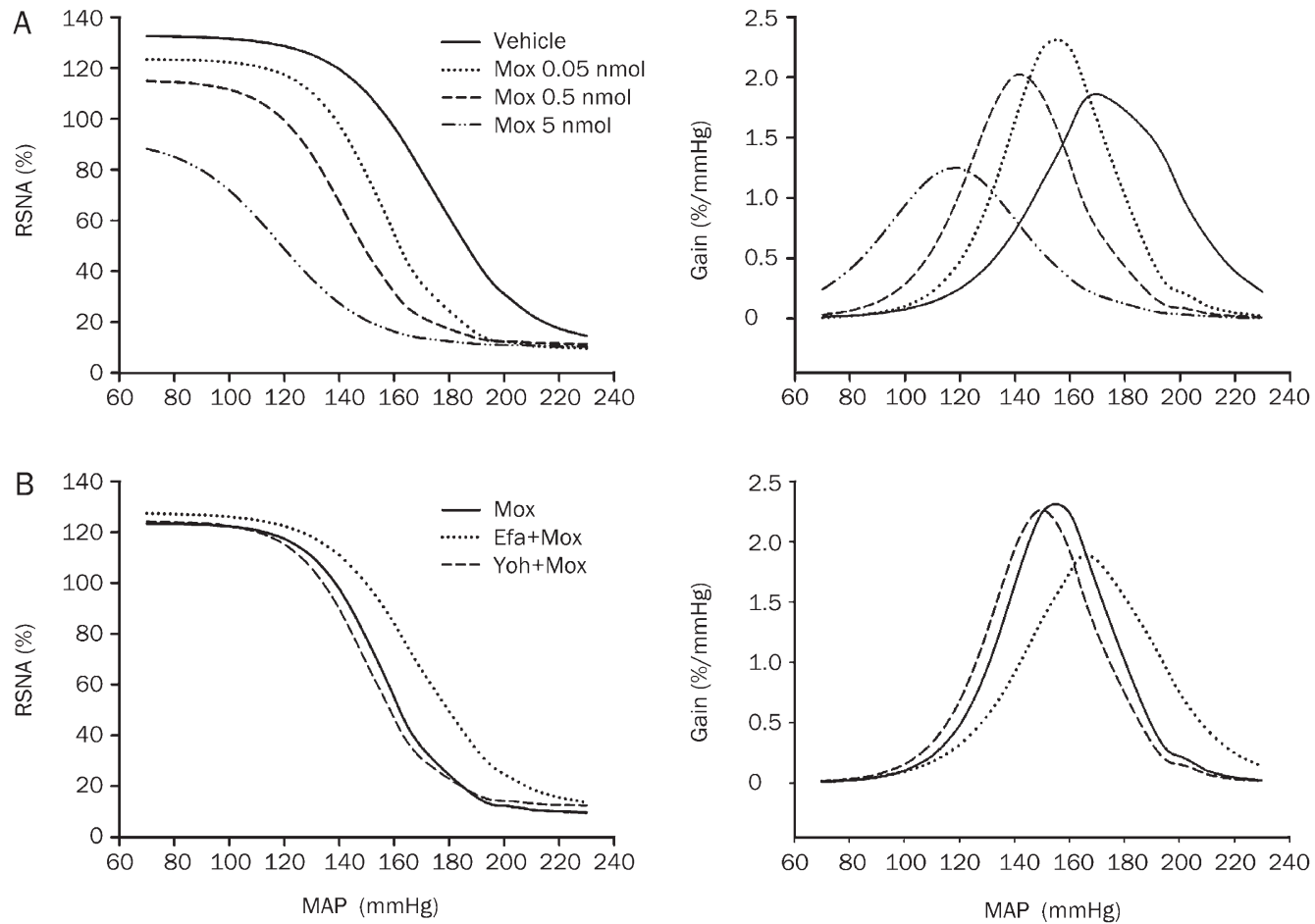

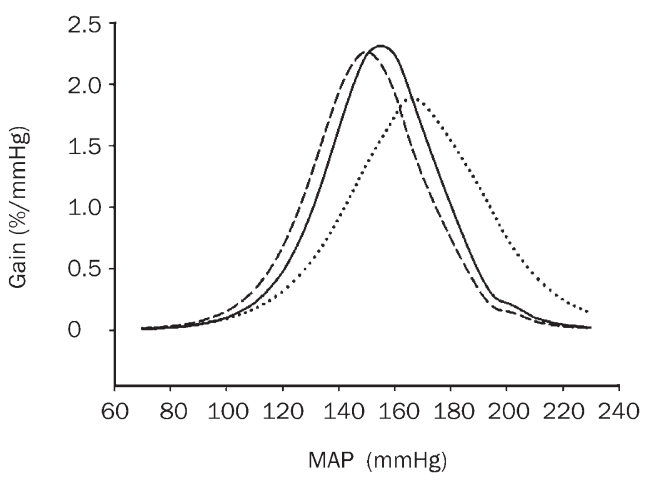

Figure 1. Effects of bilateral microinjection of moxonidine into the RVLM on baroreflex curves. Baroreflex curves (left) and average gain (right) relating RSNA to MAP after RVLM injection of three doses $(0.05,0.5$, and $5 \mathrm{nmol}$ ) of moxonidine (A) and coinjection of antagonist+0.05 nmol moxonidine (B). Mox, moxonidine; Efa, efaroxan; Yoh, yohimbine. MAP, mean arterial pressure.
As shown in Figure 1B, microinjection of efroxan (0.05 nmol) completely prevented the moxonidine $(0.05 \mathrm{nmol})$-induced increase in the gain ${ }_{\max }$ of the baroreflex control of RSNA. In contrast, pretreatment with yohimbine $(5 \mathrm{pmol})$ did not affect the moxonidine $(0.05 \mathrm{nmol})$-induced increase in baroreflex control of RSNA. In addition, both basal BP and RSNA were not significantly modified following injection of the above doses of antagonists into the RVLM.

\section{Barosensitivity of the presympathetic neurons in the RVLM}

A total of 48 units (basal discharge: $15.2 \pm 1.4$ spikes/s) in 22 SHR rats were recorded in the RVLM, and these neurons had the typical electrophysiological characteristics of presympathetic neurons: barosensitivity and spinal cord projection (Figure 2). Iontophoresis of moxonidine ( 30 and $60 \mathrm{nA}, n=48$ ) dose-dependently decreased the basal discharge of RVLM presympathetic neurons (Figure 3A). Twenty five units (16.1 11.3 spikes/s) were detected for their response of barosensitivity to moxonidine. After iontophoretic application $(30 \mathrm{nA})$ of moxonidine, the degree of discharge attenuation in response to the MAP elevation with aortic occlusion was significantly $(P<0.05)$ increased compared to the control level (Figure 2A and B). An elevation in MAP by aortic occlusion before and after moxonidine application was similar $(50.4 \pm 0.8$ vs $50.1 \pm 0.9$ $\mathrm{mmHg}, P>0.05)$. The slope of correlation between changes in MAP and neuronal discharge was significantly different (from $-0.12 \pm 0.02$ to $-0.21 \pm 0.03$ spikes $/ \mathrm{mmHg}, P<0.05$ ) before and after moxonidine application (Figure $3 \mathrm{~B}$ ), suggesting that moxonidine enhances the barosensitivity of RVLM presympathetic neurons.

\section{Discussion}

In addition to sympathetic inhibition, the centrally-acting drugs clonidine, rilmenidine, and moxonidine, have been reported to have an influence on baroreflex sensitivity ${ }^{[25-31]}$. However, it appears that the effect of these centrally-acting drugs on baroreflex sensitivity control of sympathetic activity or HR is somewhat controversial. The exact reason for the differential effects on baroreflex has not been clarified yet. It is well known that sympathoexcitation is a hallmark of hypertension ${ }^{[32,33]}$. Effective restoration of the blunted baroreflex sensitivity also is an important therapeutic strategy for hypertension ${ }^{[34-36]}$. Confirmation of the effects of centrallyacting drugs, especially second generation drugs (eg moxonidine), on baroreflex sensitivity would be important for advancing the possibility of their use in the treatment of hypertension. Previous studies ${ }^{[25,28]}$ have demonstrated that central or systemic application of centrally-acting drugs enhances the baroreflex sensitivity control of HR. However, the effect of central moxonidine on baroreflex sensitivity control of sympathetic activity, another important component of baroreflex function, has not been extensively defined at the level of the RVLM, especially on the presympathetic neuron. Therefore, this work was designed to assess the effects of several doses of moxonidine on baroreflex control of RSNA.

Moxonidine has been demonstrated to produce hypotensive and sympathoinhibitory effects through selectively stimulating $\mathrm{I}_{1} \mathrm{R}$ in the central nervous system ${ }^{[3]}$. The affinity of moxonidine at $\mathrm{I}_{1} \mathrm{R}$ is at least 40 -fold higher than its affinity at $\mathrm{a}_{2} \mathrm{AR}$, and moxonidine has been recognized as a selective agonist for $\mathrm{I}_{1} \mathrm{R}^{[3,37]}$. The current data show that, in SHR, local application of moxonidine within the RVLM significantly pro- 

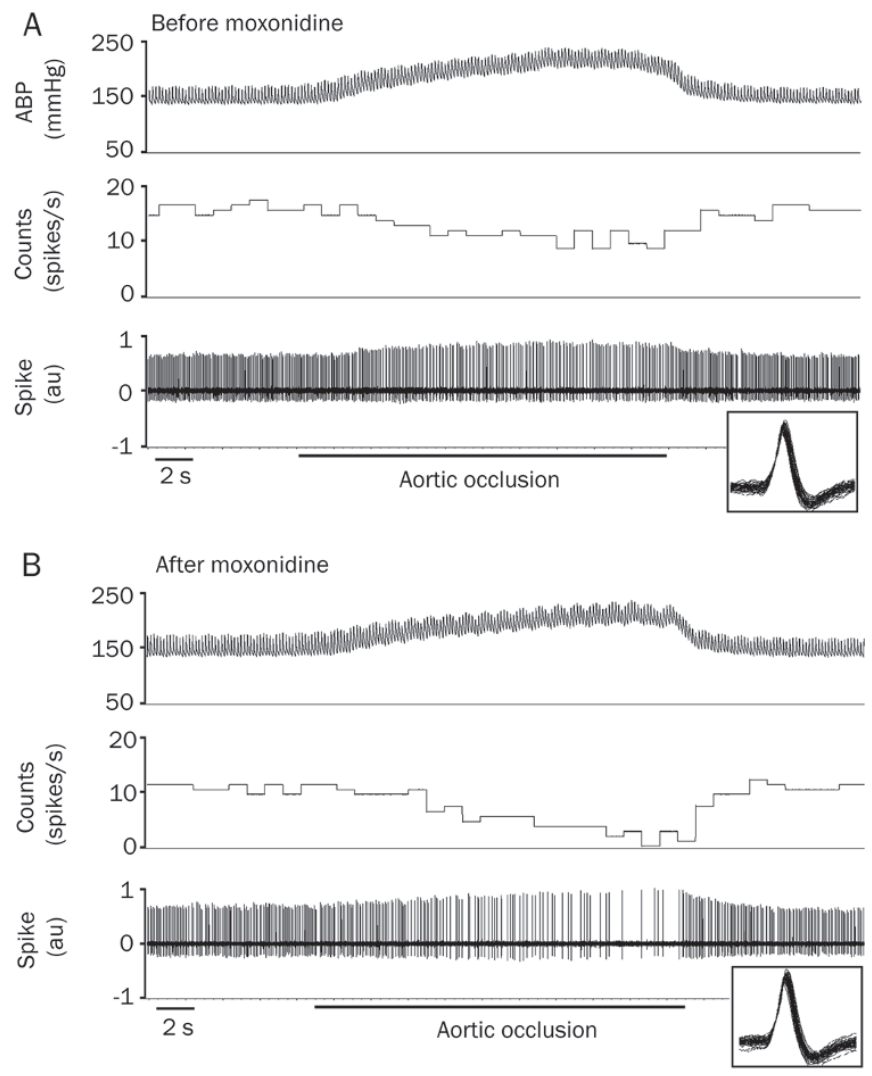

C

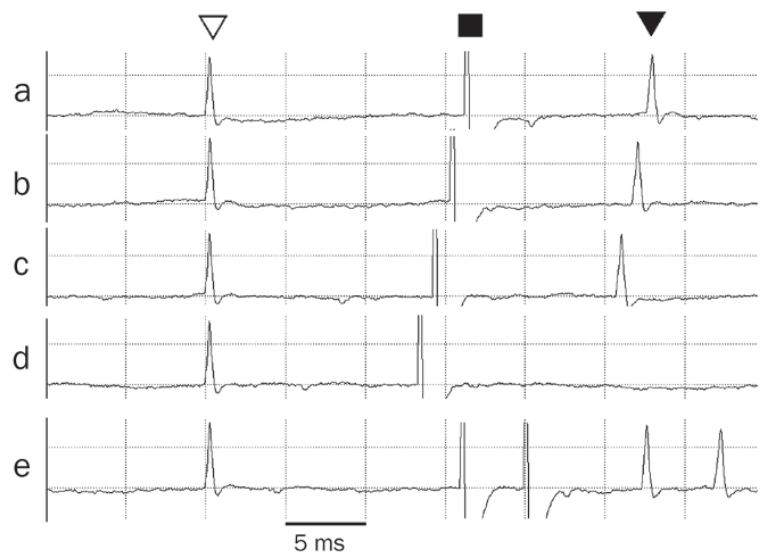

Figure 2. Effects of iontophoretic application of moxonidine (30 nA) on the barosensitivity of a presympathetic neuron in the RVLM. The discharge of an RVLM presympathetic neuron in response to a similar increase in arterial blood pressure (ABP) induced by aortic occlusion before $(\mathrm{A})$ and after (B) moxonidine application. au, arbitrary unit. Insert, the overlay (50 sweeps) of the action potential trajectories of a tested neuron. Panel $C$ shows the antidromic stimulation in the spinal cord and collision test for identification of the presympathetic neuron tested in Panel A. The spinal cord stimulation ( $\mathbf{\square}, 0.4 \mathrm{~mA}, 200 \mu \mathrm{s})$ triggered with a spontaneous spike $(\boldsymbol{\nabla})$ evoked an action potential $(\nabla)$ with constant latency $(a, b$, and c). When stimulus was applied $13 \mathrm{~ms}$ after a spontaneous spike, the antidromic spike was cancelled (d). High-frequency following test was also detected (e).

duces a significant fall in BP, RSNA, and discharge of RVLM
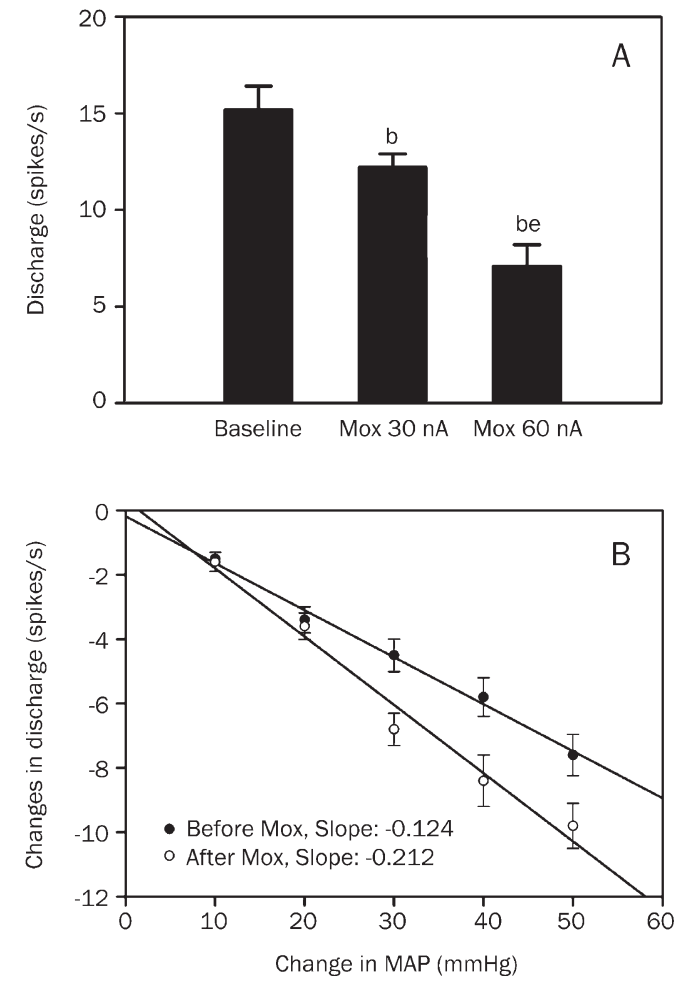

Figure 3. Effects of iontophoretic application of moxonidine on resting discharge and barosensitivity of the presympahetic neurons in the RVLM. (A) spontaneous discharge of units $(n=48)$ in response to iontophoresis of moxonidine (30 and $60 \mathrm{nA}$ ). Mox, moxonidine. ${ }^{\mathrm{b}} P<0.05$ vs baseline; ${ }^{\mathrm{e}} \mathrm{P}<0.05$ vs $30 \mathrm{nA}$ moxonidine. (B) correlation (slope) of changes between MAP and neuronal discharge before and after moxonidine application (30 $\mathrm{nA}, n=25)$. MAP, mean arterial pressure.

presympathetic neurons. It is suggested that moxonidine has an inhibitory effect on sympathetic outflow in SHR, which is consistent with previous studies elsewhere ${ }^{[3,4]}$. Interestingly, we found that the highest dose of moxonidine $(5 \mathrm{nmol})$ bilaterally injected into the RVLM produced a significant reduction in gain $_{\max }$ of baroreflex control of RSNA. In contrast, the low doses $(0.05$ and $0.5 \mathrm{nmol})$ of moxonidine in the RVLM led to an increase in gain max $_{\max }$ of baroreflex in SHR. Because the effect of low doses of moxonidine is dose-dependent and effectively prevented by the $I_{1} R$ and $a_{2} A R$ mixed antagonist efaroxan ${ }^{[3]}$ but not the selective $a_{2} A R$ antagonist yohimbine ${ }^{[38]}$, its effect is believed to be dependent on an $I_{1} R$ mechanism. There may be a limitation because we just tested the low dose group of antagonists in response to beneficial effect of the low dose of moxonidine on baroreflex. At least, our data suggested that the enhanced baroreflex induced by the low dose of moxonidine is related to activation of $I_{1} R$ in the RVLM. In fact, $I_{1} R$ but not $\mathrm{a}_{2} \mathrm{AR}$ mechanism has been widely demonstrated to be responsible for the effects of moxonidine, especially in the RVLM. Importantly, we also detected the barosensitivity of RVLM presympathetic neurons in response to a small amount of moxonidine application by iontophoresis, because these neurons play a crucial role in the tonic and reflex control of 
sympathetic outflow ${ }^{[39]}$. Clearly, iontophoretic application of moxonidine significantly enhanced the barosensitivity of RVLM presympathetic neurons. Based on the present data, it is suggested that a low dose of moxonidine is capable of improving the baroreflex sensitivity in the hypertension state. The exact reason for opposite responses of baroreflex sensitivity control of RSNA to different doses of moxonidine application in the RVLM is not clear. One possibility is that the basal levels of BP and RSNA account for different baroreflex responses to moxonidine. Ten minutes after 5 nmol of moxonidine injection into the RVLM, when the baroreflex measurement was carried out, the basal BP and RSNA still are lower compared with the control levels. However, the basal values were completely and partially restored to control level $10 \mathrm{~min}$ after 0.05 and $0.5 \mathrm{nmol}$ of moxonidine injections, respectively. The low levels of basal BP and RSNA significantly shift the baroreflex curve left, shorten the range of RSNA or maximum RSNA, and reduce MAP at midpoint, which has been similarly described in previous studies ${ }^{[8,40,41]}$. Therefore, the baroreflex measurements were performed at different basal values for MAP and RSNA before and after moxonidine injections into the RVLM. These lower basal levels of baroreflex parameters would have a significant inhibitory influence on baroreflex measurement and reduce the gain max $_{\max }$ of the baroreflex. In contrast, the basal values for MAP and RSNA were partially or completely recovered $10 \mathrm{~min}$ after low $(0.05$ and $0.5 \mathrm{nmol})$ dose of moxonidine injection in this study. It may be more accurate at similar basal values before and after moxonidine treatment. We used the slope of correlation of changes between MAP and neuronal discharge to further detect barosensitivity of the RVLM units in response to iontophoretic moxonidine. Although the basal discharge was reduced to some extent, the basal BP was not significantly changed during iontophoresis of moxonidine. It is clearly shown that iontophoretic moxonidine improves barosensitivity of presympathetic neurons in the RVLM. Another possibility is that different receptor $\left(\mathrm{I}_{1} \mathrm{R}\right.$ and $\left.\mathrm{a}_{2} \mathrm{AR}\right)$ activation following moxonidine results in differential responses of baroreflex sensitivity. Although moxonidine has a much higher affinity for $I_{1} R$ than $a_{2} A R$ and is generally accepted as a selective agonist for $I_{1} R$, $\mathrm{a}_{2} \mathrm{AR}$ is not completely excluded for moxonidine actions. It is reported that $\mathrm{a}_{2} \mathrm{AR}$ is involved in mediating baroreflex control and the $\mathrm{a}_{2} \mathrm{AR}$ and $\mathrm{I}_{1} \mathrm{R}$ mixed agonist clonidine (first generation centrally-acting drug) also modifies baroreflex sensitivity ${ }^{[42-44]}$. We did not completely exclude the possibility that a high dose of moxonidine also stimulates $\mathrm{a}_{2} \mathrm{AR}$ besides $\mathrm{I}_{1} R$ in the RVLM. A recent study shows that $\mathrm{a}_{2} \mathrm{AR}$ activation is required, at least partially, for the cardiovascular response to moxonidine in the $\mathrm{RVLM}^{[45]}$. Therefore, it is possible that $\mathrm{a}_{2} \mathrm{AR}$ activation interferes with the effect of $\mathrm{I}_{1} R$ activation on baroreflex following a high dose of moxonidine. The interaction between $\mathrm{a}_{2} \mathrm{AR}$ and $\mathrm{I}_{1} \mathrm{R}$ was also reported to contribute to the effects of centrallyacting drugs ${ }^{[46]}$. Furthermore, Head et al report that blockade of $\mathrm{a}_{2} \mathrm{AR}$ in the RVLM reverses the effect of the centrally-acting drug rilmenidine (high affinity for $\mathrm{I}_{1} \mathrm{R}$ ) on baroreflex sensitivity in rabbit ${ }^{[47]}$. However, the present study shows that the enhancement of a low dose of moxonidine on baroreflex sensitivity is not affected by the selective $\mathrm{a}_{2} \mathrm{AR}$ antagonist yohimbine. Therefore, the effect of the interaction between $I_{1} R$ and $\mathrm{a}_{2} \mathrm{AR}$ activation on baroreflex sensitivity needs to be defined in future studies.

In summary, the present study showed that moxonidine application within the RVLM reduced the resting BP, RSNA, and discharge of presympathetic neurons in SHR. We further observed that the lower dose of moxonidine in the RVLM significantly improved baroreflex control of RSNA and barosensitivity of presympathetic neurons, which is dependent on an $\mathrm{I}_{1} \mathrm{R}$ mechanism.

\section{Acknowledgements}

This work was supported by the National Natural Science Foundation of China (№ 30670759 and 30971061) and the Major State Basic Research Development Program of China (No 2006CB503807). This work was also supported by the grant from the Science and Technology Commission of Shanghai (№ 06QB14029 and 09PJ1400100).

\section{Author contribution}

Wei-zhong WANG, Wen-jun YUAN and Xin NI designed research; Jia-ling WANG, Long WANG and Jian-jun YAN performed research; Ding-feng SU contributed new analytical tools and reagents; Zhao-tang WU analyzed data; Wei-zhong WANG and Jian-jun YAN wrote the paper.

\section{References}

1 Ernsberger P, Damon TH, Graff LM, Schafer SG, Christen MO. Moxonidine, a centrally acting antihypertensive agent, is a selective ligand for I I $_{1}$-imidazoline sites. J Pharmacol Exp Ther 1993; 264: 172-82.

2 Dampney RA. Functional organization of central pathways regulating the cardiovascular system. Physiol Rev 1994; 74: 323-64.

3 Haxhiu MA, Dreshaj I, Schafer SG, Ernsberger P. Selective antihypertensive action of moxonidine is mediated mainly by $I_{1}$-imidazoline receptors in the rostral ventrolateral medulla. J Cardiovasc Pharmacol 1994; 24 Suppl 1: S1-S8.

4 Reis DJ. Neurons and receptors in the rostroventrolateral medulla mediating the antihypertensive actions of drugs acting at imidazoline receptors. J Cardiovasc Pharmacol 1996; 27 Suppl 3: S11-S18.

5 Collier DJ, Bernardi L, Angell-James JE, Caulfield MJ, Sleight P. Baroreflex sensitivity and heart rate variability as predictors of cardiovascular outcome in hypertensive patients with multiple risk factors for coronary disease. J Hum Hypertens 2001; 15 Suppl 1: S57-S60.

6 Johansson M, Gao SA, Friberg P, Annerstedt M, Carlstrom J, Ivarsson T, et al. Baroreflex effectiveness index and baroreflex sensitivity predict all-cause mortality and sudden death in hypertensive patients with chronic renal failure. J Hypertens 2007; 25: 163-8.

7 Su DF, Miao CY. Reduction of blood pressure variability: a new strategy for the treatment of hypertension. Trends Pharmacol Sci 2005; 26: 388-90.

8 Head GA. Baroreflexes and cardiovascular regulation in hypertension. J Cardiovasc Pharmacol 1995; 26 Suppl 2: S7-16.

9 Harron DW. Antihypertensive drugs and baroreflex sensitivity. Effects of rilmenidine. Am J Med 1989; 87: 57S-62S.

10 Medvedev OS, Kunduzova OR, Murashev AN, Medvedeva NA. Influence of sino-aortic barodenervation on the cardiovascular effects 
of imidazoline-like drugs. J Auton Nerv Syst 1998; 72: 205-9.

11 Mancia G, Ferrari A, Gregorini L, Zanchetti A. Clonidine and carotid baroreflex in essential hypertension. Hypertension 1979; 1: 362-70.

12 Head GA, Burke SL, Sannajust FJ. Involvement of imidazoline receptors in the baroreflex effects of rilmenidine in conscious rabbits. J Hypertens 2001; 19: 1615-24.

13 Mayorov DN, Burke SL, Head GA. Relative importance of rostral ventrolateral medulla in sympathoinhibitory action of rilmenidine in conscious and anesthetized rabbits. J Cardiovasc Pharmacol 2001; 37: 252-61.

14 Head GA, Burke SL. Comparison of renal sympathetic baroreflex effects of rilmenidine and alpha-methylnoradrenaline in the ventrolateral medulla of the rabbit. J Hypertens 2000; 18: 1263-76.

15 Tank J, Jordan J, Diedrich A, Obst M, Plehm R, Luft FC, et al. Clonidine improves spontaneous baroreflex sensitivity in conscious mice through parasympathetic activation. Hypertension 2004; 43: 1042-7.

16 Ma XJ, Shen FM, Liu AJ, Shi KY, Wu YL, Su DF. Clonidine, moxonidine, folic acid, and mecobalamin improve baroreflex function in strokeprone, spontaneously hypertensive rats. Acta Pharmacol Sin 2007; 28: $1550-8$.

17 Wang LG, Zeng J, Yuan WJ, Su DF, Wang WZ. Comparative study of NMDA and AMPA/kainate receptors involved in cardiovascular inhibition produced by imidazoline-like drugs in anaesthetized rats. Exp Physiol 2007; 92: 849-58.

18 Wang WZ, Yuan WJ, Tang CS, Su DF. Electrophysiological evidences for the contribution of NMDA receptors to the inhibition of clonidine on the RVLM presympathetic neurons. Brain Res 2004; 1023: 163-6.

19 Brown DL, Guyenet PG. Electrophysiological study of cardiovascular neurons in the rostral ventrolateral medulla in rats. Circ Res 1985; 56: 359-69.

20 Lipski J, Kanjhan R, Kruszewska B, Rong W. Properties of presympathetic neurones in the rostral ventrolateral medulla in the rat: an intracellular study "in vivo". J Physiol 1996; 490 ( Pt 3): 729-44.

21 Goodchild AK, Dampney RA, Bandler R. A method for evoking physiological responses by stimulation of cell bodies, but not axons of passage, within localized regions of the central nervous system. J Neurosci Methods 1982; 6: 351-63.

22 Paxions G WC. The rat brain in stereotaxic coordinates (4th ed). New York: Academic press; 1998.

23 Wang LG, Zeng J, Yuan WJ, Su DF, Wang WZ. Comparative study of NMDA and AMPA/kainate receptors involved in cardiovascular inhibition produced by imidazoline-like drugs in anaesthetized rats. Exp Physiol 2007; 92: 849-58.

24 Wang WZ, Yuan WJ, Ren AJ, Pan YX, Tang CS, Su DF. Role of $\mathrm{I}_{1}$-imidazoline receptors within the caudal ventrolateral medulla in cardiovascular responses to clonidine in rats. J Cardiovasc Pharmacol 2003; 42: 1-9.

25 Tank J, Jordan J, Diedrich A, Obst M, Plehm R, Luft FC, et al. Clonidine improves spontaneous baroreflex sensitivity in conscious mice through parasympathetic activation. Hypertension 2004; 43: 1042-7.

26 Harron DW. Antihypertensive drugs and baroreflex sensitivity. Effects of rilmenidine. Am J Med 1989; 87: 57S-62S.

27 Mancia G, Ferrari A, Gregorini L, Zanchetti A. Clonidine and carotid baroreflex in essential hypertension. Hypertension 1979; 1: 362-70.

28 Su DF, Miao CY. Reduction of blood pressure variability: a new strategy for the treatment of hypertension. Trends Pharmacol Sci 2005; 26: 388-90.

29 Head GA, Burke SL, Sannajust FJ. Involvement of imidazoline receptors in the baroreflex effects of rilmenidine in conscious rabbits.
J Hypertens 2001; 19: 1615-24.

30 Mayorov DN, Burke SL, Head GA. Relative importance of rostral ventrolateral medulla in sympathoinhibitory action of rilmenidine in conscious and anesthetized rabbits. J Cardiovasc Pharmacol 2001; 37: 252-61.

31 Head GA, Burke SL. Comparison of renal sympathetic baroreflex effects of rilmenidine and alpha-methylnoradrenaline in the ventrolateral medulla of the rabbit. J Hypertens 2000; 18: 1263-76.

32 Anderson EA, Sinkey CA, Lawton WJ, Mark AL. Elevated sympathetic nerve activity in borderline hypertensive humans. Evidence from direct intraneural recordings. Hypertension 1989; 14: 177-83.

33 Judy WV, Watanabe AM, Henry DP, Besch HR Jr, Murphy WR, Hockel GM. Sympathetic nerve activity: role in regulation of blood pressure in the spontaneously hypertensive rat. Circ Res 1976; 38: 21-9.

34 Johansson M, Gao SA, Friberg P, Annerstedt M, Carlstrom J, Ivarsson T, et al. Baroreflex effectiveness index and baroreflex sensitivity predict all-cause mortality and sudden death in hypertensive patients with chronic renal failure. J Hypertens 2007; 25: 163-8.

35 La Rovere MT, Pinna GD, Hohnloser SH, Marcus FI, Mortara A, Nohara R, et al. Baroreflex sensitivity and heart rate variability in the identification of patients at risk for life-threatening arrhythmias: implications for clinical trials. Circulation 2001; 103: 2072-7.

36 Su DF, Miao CY. Reduction of blood pressure variability: a new strategy for the treatment of hypertension. Trends Pharmacol Sci 2005; 26: 388-90.

37 Ernsberger P, Damon TH, Graff LM, Schafer SG, Christen MO. Moxonidine, a centrally acting antihypertensive agent, is a selective ligand for $\mathrm{I}_{1}$-imidazoline sites. J Pharmacol Exp Ther 1993; 264: 172-82.

38 Goldberg MR, Robertson D. Yohimbine: a pharmacological probe for study of the alpha 2-adrenoreceptor. Pharmacol Rev 1983; 35 : 143-80.

39 Dampney RA. Functional organization of central pathways regulating the cardiovascular system. Physiol Rev 1994; 74: 323-64.

40 Head GA, Burke SL. Comparison of renal sympathetic baroreflex effects of rilmenidine and alpha-methylnoradrenaline in the ventrolateral medulla of the rabbit. J Hypertens 2000; 18: 1263-76.

41 Head GA, Burke SL, Sannajust FJ. Involvement of imidazoline receptors in the baroreflex effects of rilmenidine in conscious rabbits. J Hypertens 2001; 19: 1615-24.

42 Ma XJ, Shen FM, Liu AJ, Shi KY, Wu YL, Su DF. Clonidine, moxonidine, folic acid, and mecobalamin improve baroreflex function in strokeprone, spontaneously hypertensive rats. Acta Pharmacol Sin 2007; 28: 1550-8.

43 Mancia G, Ferrari A, Gregorini L, Zanchetti A. Clonidine and carotid baroreflex in essential hypertension. Hypertension 1979; 1: 362-70.

44 Tank J, Jordan J, Diedrich A, Obst M, Plehm R, Luft FC, et al. Clonidine improves spontaneous baroreflex sensitivity in conscious mice through parasympathetic activation. Hypertension 2004; 43: 1042-7.

45 Moreira TS, Takakura AC, Menani JV, Colombari E. Involvement of central alpha1- and alpha2-adrenoceptors on cardiovascular responses to moxonidine. Eur J Pharmacol 2007; 563: 164-71.

46 Bruban V, Estato V, Schann S, Ehrhardt JD, Monassier L, Renard $\mathrm{P}$, et al. Evidence for synergy between alpha(2)-adrenergic and nonadrenergic mechanisms in central blood pressure regulation. Circulation 2002; 105: 1116-21.

47 Head GA, Burke SL. Comparison of renal sympathetic baroreflex effects of rilmenidine and alpha-methylnoradrenaline in the ventrolateral medulla of the rabbit. J Hypertens 2000; 18: 1263-76. 